\title{
Studi Akuifer dengan Metode Geolistrik Resistivitas Desa Dadapan Kendal, Ngawi-Jawa Timur
}

\author{
Fajar Rakhmanto ${ }^{1}$, Nicho Andreas Fernando ${ }^{2}$ \\ ${ }^{1}$ Program Studi Teknik Elektro, Fakultas Teknik, Sekolah Tinggi Teknik Industri Turen \\ ${ }^{2}$ Program Studi Ilmu Geografi, Fakultas Ilmu Sosial, Universitas Negeri Malang \\ ${ }^{1}$ phajar.geoub@gmail.com, ${ }^{2}$ ohcin.fernand@gmail.com
}

\begin{abstract}
ABSTRAK
Pengukuran geolistrik dilakukan di Desa Dadapan Kecamatan Kendal Kabupaten Ngawi Jawa Timur sejumlah 3 (tiga) titik pengukuran VES (Vertical Electrical Sonding). Hasil pengukuran geolistrik dan data geologi menunjukkan kondisi batuan merupakan satuan Batuapung, Breksi/Andesit dan Batuapung berpasir. Nilai resistivitas yang menunjukkan akuifer pada range 50 - $200 \mathrm{Ohm}$ meter yang terdapat pada batuapung berpasir. Tiga titik pengukuran menunjukkan lapisan akuifer dalam pada batuapung berpasir miring ke titik DDP-3 dengan kedalaman $71-180$ meter.
\end{abstract}

Kata kunci : desa dadapan kendal; VES (Vertical electrical Sonding; akuifer; batuapung berpasir

\begin{abstract}
Geoelectric measurements in Dadapan Village, Kendal District, Ngawi Regency, East Java were 3 (three) measurement points of VES (Vertical Electrical Sonding). Geoelectric measurement results and geological data indicate rock conditions are units of Pumice, Breccia / Andesite and sandy Pumice. Resistivity values that indicate aquifers in the range 50 - 200 Ohm meters are found in sandy pumice. Three measurement points show the inner aquifer layer in the sloping sandstone to the DDP-3 point with a depth of $71-180$ meter.
\end{abstract}

Keywords : dadapan kendal village; VES (Vertical electrical Sonding), aquifer, sandy pumice

\section{PENDAHULUAN}

Petumbuhan penduduk di Kecamatan Kendal Kabupaten Ngawi menurut Badan Statistik Kabupaten Ngawi $0.15 \%$. Artinya, peningkatan penduduk dapat mempengaruhi peningkatan konsumsi kebutuhan pokok primer. Salah satu kebutuhan primer yang harus terpenuhi yaitu ketersediaan air bersih. Untuk memenuhi kebutuhan air bersih, umumnya air bawah tanah dijadikan sebagai pilihan karena dianggap lebih bersih dan mudah didapat. Tetapi kenyataannya untuk mendapatkan air bawah tanah tidak mudah dan bahkan menjadi masalah yang cukup serius dibeberapa daerah, terutama daerah yang memiliki kuantitas air bawah tanah yang terbatas. Kuantitas air bawah tanah sangat dipengaruhi oleh curah hujan, kondisi 
geologi, topografi dan kondisi vegetasi pada suatu daerah. [1]

\section{Kecamatan Kendal Kabupaten} Ngawi Jawa Timur merupakan salah satu daerah padat penduduk, sehingga sarat akan kebutuhan air bersih dan air baku. Dilihat dari tata ruang kota, daerah Ngawi merupakan kawasan pemukiman, industri kecil-menengah, perternakan dan perkebun-an yang berada di Jawa Timur.

Guna mengimbangi kebutuhan air bersih dan air baku untuk kebutuhan masyarakat di Kecamatan Kendal Kabupaten Ngawi, maka perlu dilakukan penelitian lebih lanjut mengenai keberadaan air bersih dan air baku. Dalam upaya penelitian tersebut, digunakan metode geolistrik resistivitas guna mengetahui kondisi geologi dan lapisan akuifer (penyimpan air) daerah tersebut. Metode geolistrik resistivitas merupakan salah satu metode dengan menggunakan pendekatan fisika untuk membedakan sifat hambatan listrik batuan. Hal tersebut yang dipergunakan dalam menggambarkan suatu lapisan batuan, apakah dapat penyimpan air maupun sebaliknnya.

Tujuan penelitian dan pengukuran geolistrik resistivitas Desa Dadapan Kecamatan Kendal ini mempunyai beberapa tujuan, antara lain :

1. Mengetahui lapisan akuifer di lokasi penelitian

2. Mengetahui sebaran lapisan akuifer dan akumulasi akufer daerah penelitian.

3. Menentukan titik kedalaman lapisan akuifer.

\section{METODE KEGIATAN}

Geolistrik resistivitas merupakan metode pendugaan struktur lapisan batuan bawah permukaan bumi berdasarkan nilai resistivitas setiap jenis batuan yang terukur saat diberikan arus listrik yang dimasukkan ke dalam bumi melalui 2 elektroda arus. Arus listrik yang mengalir melalui 2 elektroda menghasilkan beda potensial yang dapat diukur menggunakan dua elektroda potensial. Hasil pengukuran arus dan beda potensial setiap jarak elektroda menghasilkan variasi harga hambatan jenis masing-masing lapisan batuan di bawah titik ukur.

Metode resistivitas didasarkan pada kenyataan bahwa sebagian dari arus listrik yang diberikan pada lapisan tanah, ternetrasi pada kedalaman tertentu dan bertambah besar dengan bertambahnya jarak antar elektrode, sehingga jika sepasang elektrode diperbesar, distribusi potensial pada permukaan bumi akan semakin membesar dengan nilai resistivitas yang bervariasi [1].

Pengukuran geolistrik resistivitas pada Desa dadapan Kecamatan kendal Ngawi menggunakan metode geolistrik resistivitas konfigurasi Schlumberger. Prinsip kerja metode tersebut dengan menggunakan 4 elektroda, masingmasing 2 elektroda arus dan 2 elektroda potensial. Untuk konfigurasi Schlumberger memiliki jarak $\mathrm{AB}>3 \mathrm{MN}$ (lihat gambar 1). Hal ini bertujuan untuk mencatat gradient potensial dimana elektroda potensialnya berjarak pendek. Dalam skema konfigurasi Schlumberger yang ditunjukkan pada gambar 1, MN adalah elektroda potensial sedangkan $\mathrm{AB}$ 
adalah elektroda arus dan $\mathrm{O}$ adalah titik tengah konfigurasi. Jarak r3 (elektroda potensial $\mathrm{N}$ terhadap elektroda arus $\mathrm{A}$ ) sama dengan jarak $\mathrm{r} 2$ (elektroda potensial M ke elektroda B). Sedangkan jarak r1 (elektroda potensial $\mathrm{M}$ terhadap elektroda arus A) sama dengan jarak r4 (elektroda potensial $\mathrm{N}$ terhadap elektroda arus $\mathrm{B}$ ). Konfigurasi ini sering digunakan untuk pengukuran vertical sounding karena penerapannya lebih praktis. [2]

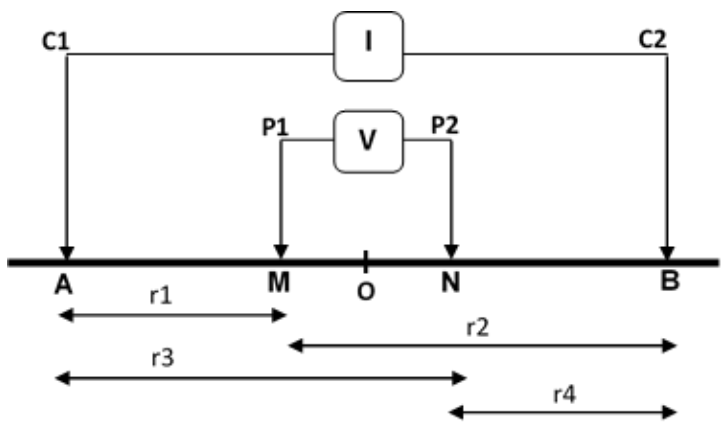

Gambar 1. Konfigurasi Schlumberger

Tahanan jenis semu medium yang terukur dihitung berdasarkan persamaan [3]

$$
\begin{gathered}
\rho=K \frac{\Delta V}{I}=K \frac{\frac{I \rho}{\pi}\left(\frac{4 M N}{A B^{2}-M N^{2}}\right)}{I} \\
K=\pi\left(\frac{A B^{2}-M N^{2}}{4 M N}\right)
\end{gathered}
$$

Keterangan :

$\rho:$ : tahanan terukur (apparent resistivity)

$\Delta \mathrm{V}$ : potensial yang terukur antara elektroda P1 dan P2

I : arus listrik yang mengalir ke tanah melalui elektroda $\mathrm{C} 1$ dan $\mathrm{C} 2$

$\mathrm{K}$ : faktor geometri konfigurasi elektroda

\section{KARYA UTAMA}

Penelitian geolistrik resistivitas untuk menentukan akuifer (air bawah tanah) di Desa Dadapan Kecamatan Kendal Ngawi dilakukan pada bulan April 2017. Adapun jumlah titik penelitian geolistrik terdiri dari (tiga) titik pengukuran. Titik pengukuran geolistrik berlokasi di lapangan milik Desa Dadapan. Adapun koordinat lokasi pengukuran dapat dilihat pada Tabel 1 dan dan Gambar 2.

Tabel 1. Koordinat Lokasi Pengukuran

\begin{tabular}{|l|l|l|l|}
\hline TITIK & LOKASI & KOORDINAT & ALT \\
\hline DDP-1 & $\begin{array}{l}\text { Lapangan } \\
\text { Desa } \\
\text { Dadapan }\end{array}$ & $\begin{array}{l}\text { S7.54296 } \\
\text { E111.28079 }\end{array}$ & $\begin{array}{l}299 \\
\text { meter }\end{array}$ \\
\hline DDP-2 & $\begin{array}{l}\text { Lapangan } \\
\text { Desa } \\
\text { Dadapan }\end{array}$ & $\begin{array}{l}\text { S7.54284 } \\
\text { E111.28087 }\end{array}$ & $\begin{array}{l}298 \\
\text { meter }\end{array}$ \\
\hline DDP-3 & $\begin{array}{l}\text { Lapangan } \\
\text { Desa } \\
\text { Dadapan }\end{array}$ & $\begin{array}{l}\text { S7.54281 } \\
\text { E111.28094 }\end{array}$ & $\begin{array}{l}298 \\
\text { meter }\end{array}$ \\
\hline
\end{tabular}

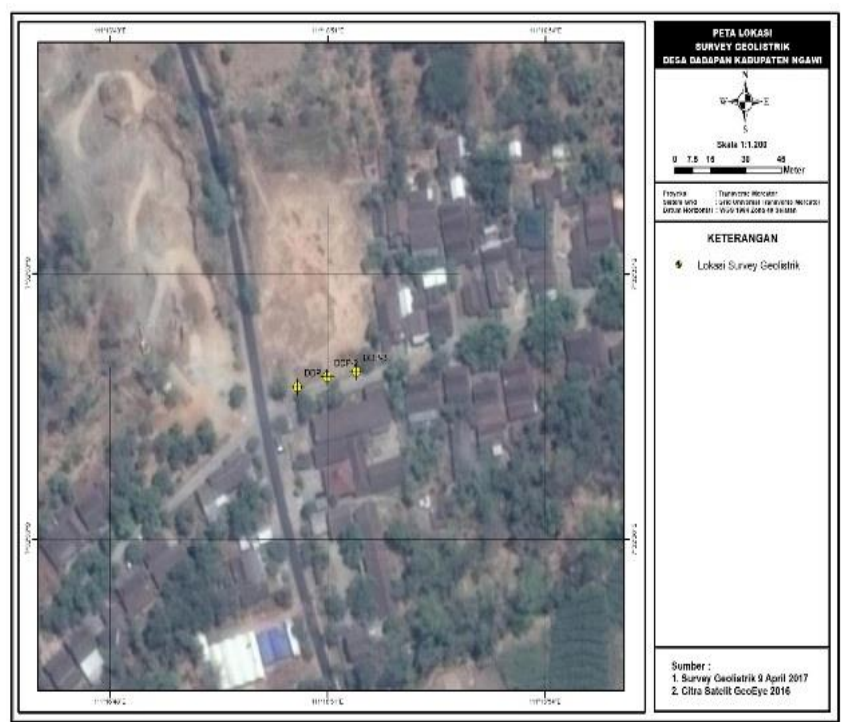

Gambar 2. Lokasi Pengukuran

\section{ULASAN KARYA}

Lokasi pengukuran geolistrik pada peta geologi terdapat pada satuan geologi 
Qlla (Endapan Gunungapi Lawu), yaitu komponen andesit, basalt, batuapung yang bercampur dengan pasir gunungapi. Sebaran terdapat dikaki gunung Lawu dan membentuk beberapa perbukitan rendah [4]. Berdasarkan kondisi geologi dilokasi maupun berdasarkan peta, diperkirakan keberadaan lapisan akuifer terdapat pada pasir gunungapi dan rekahan batuan (gambar 3).

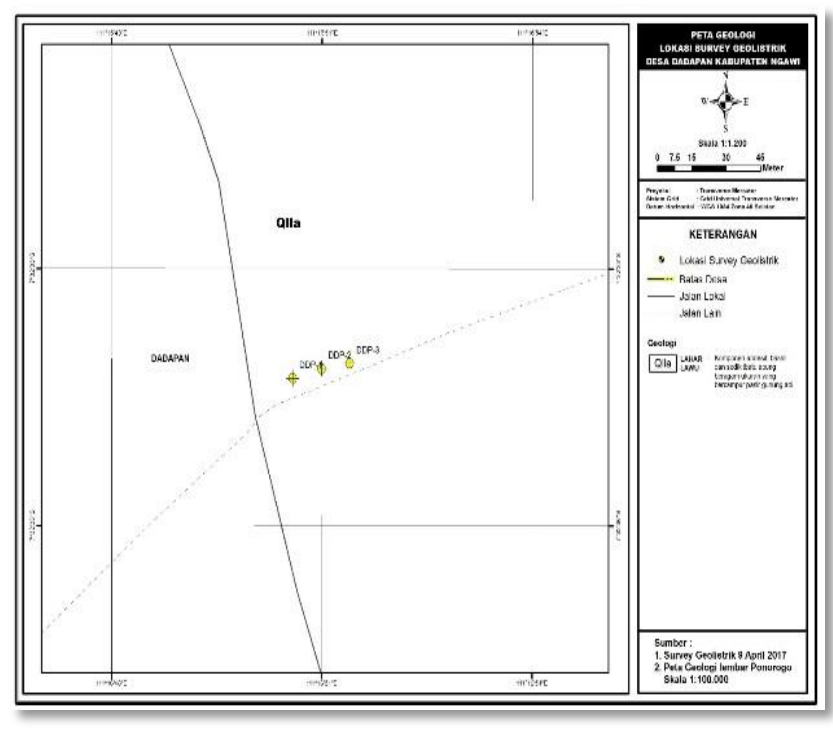

Gambar 3. Peta Geologi Daerah Pengukuran Geolistrik Desa Dadapan Kendal Ngawi

Untuk mendapatkan gambaran kondisi batuan secara vertikal, dilakukan pengolahan data geolistrik resistivitas dengan menitikberatkan pada nilai hambatan jenis semu dan dilakukan pengolahan untuk mendapatkan nilai resistivitas batuan yang sebenarnya. Jenis batuan berdasarkan nilai resistivitas dapat dilihat pada tabel 2 .

Titik geolistrik didesa Dadapan terdiri dari 3 (tiga) titik dengan kode DDP-1, DDP-2 dan DDP-3. Letak titik DDP-1 terletak disisi paling timur, selanjutnya DDP-2 disisi barat DDP-1, dan DDP-3 terletak paling barat. Lokasi pengukuran terletak dilapangan milik Desa Dadapan (samping balai desa), dimungkinkan jika pengeboran air dilakukan akan mempermudah mendapatkan ijin pengeboran air. Selain itu, letak titik pengukuran tidak jauh dari jalan raya maupun jalan desa, sehingga hal tersebut mempermudah tim ekplorasi (pengeboran) dalam melakukan tindakan teknis serta mempermudah masyarakat sebagai pengguna hasil pengeboran untuk mendapatkan air. Adapun hasil interpretasi dari survey geolistrik di Desa Dadapan sebagai berikut

\section{DDP-1}

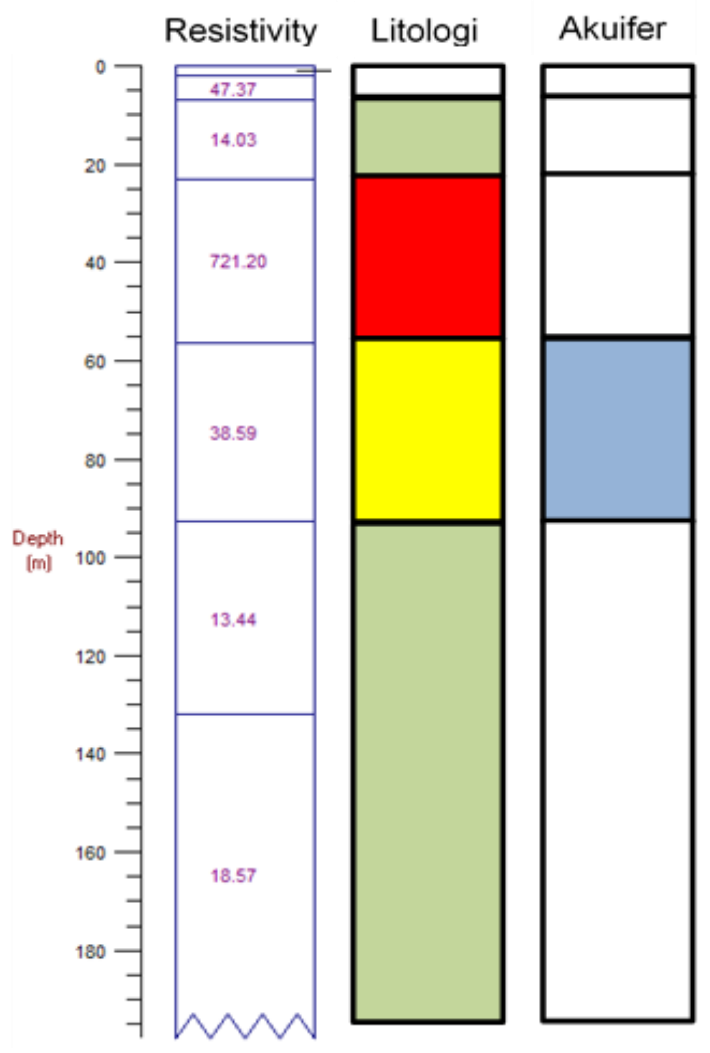


DDP-2

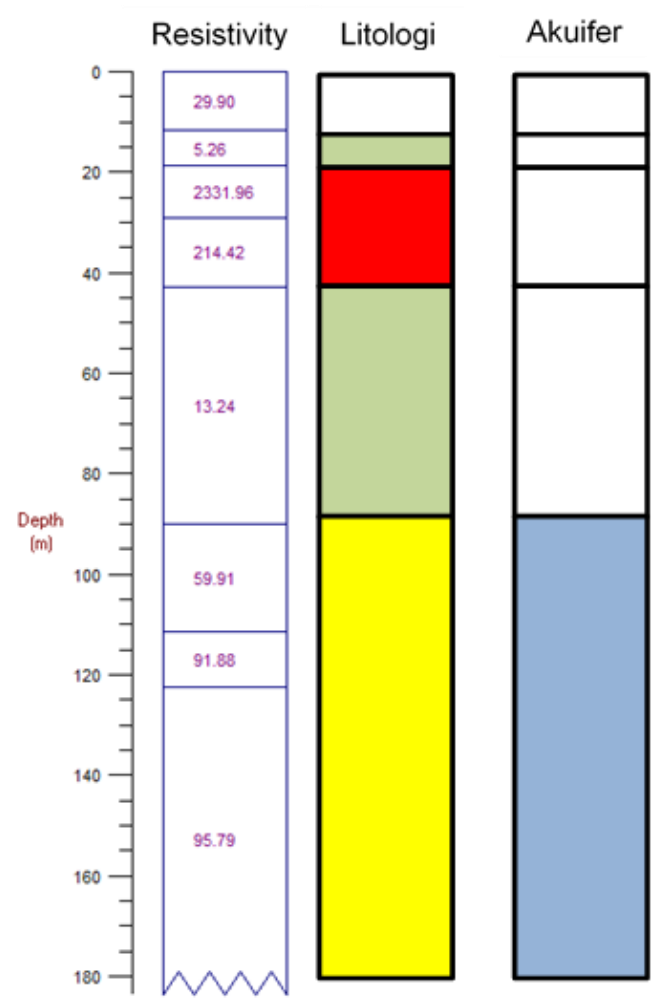

$\underline{\text { DDP-3 }}$

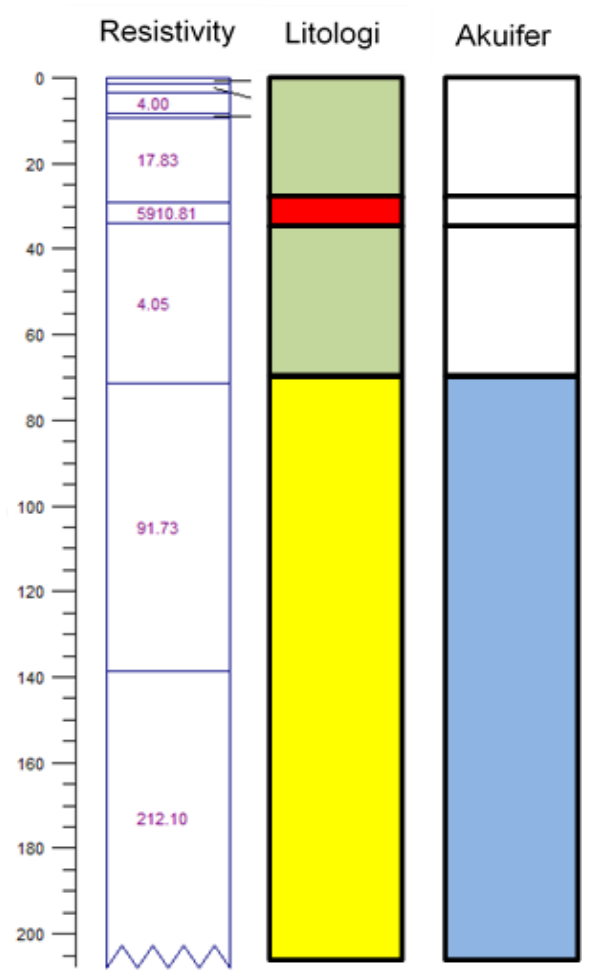

Gambar 4. Interpretasi Titik Geolistrik 1 Dimensi
Titik pengukuran pada DDP-1 menunjukkan adanya lapisan batuan yang terdiri dari batuan Breksi, Batuapung dan campuran pasir. Hasil interpretasi dari nilai resitivitas yang didapatkan menunjukkan susunan batuan Batuapung dari kedalaman 1.9-7 meter, batuapung pada kedalaman 722.9 meter, 22.9-56.5 menunjukkan batuan Breksi. Sampai kedalaman 56.5 meter menunjukkan lapisan impermiabel/kedap air. Jika terdapat air, dimungkinkan adanya rongga antar batuan. Namun pada kedalaman 56.5 131 terdapat lapisan Batuapung berpasir yang dapat diindikasi-kan sebagai akuifer/lapisan permiabel. Hal ini ditunjukkan adanya nilai resistivitas yang merujuk pada resistivitas air tanah dan pasir. Setelah lapisan permiabel tersebut yaitu 131-175 meter diidentifikasikan lapisan Batuapung bersifat impermiabel. Lapisan batu apung terakhir ini dimungkinkan sebagai lapisan kedap air bagian bawah, sehingga akuifer pada lapisan sebelumnya tidak meresap lebih dalam.

Pengukuran titik geolistrik DDP2, menunjukkan hal serupa dengan DDP-1. Namun terdapat beberapa perbedaan kedalaman dari masingmasing lapisan batuan. Adapun hasil interpretasi dari titik DDP-2 menunjukkan lapisan Soil, Batuapung berpasir, Breksi, Batuapung dan terakhir Batu apung berpasir. Kedalaman lapisan batuapung berpasir terdapat pada 11.618.8 meter, dimungkinkan pada lapisan ini terdapat akuifer dangkal. Akuifer dangkal dipengaruhi oleh musim, sehingga kurang baik jika dilakukan ekplorasi pada lapisan ini. Selanjutnya 
terdapat lapisan Breksi pada kedalaman 18.8-42 meter, dan Batuapung dikedalaman 42-89 meter. Pada kedalaman 18.8-89 meter tidak direkomendasikan untuk dilakukan pengambilan akuifer, karena batuan tersebut bersifat imoermiabel/kedap air, sehingga tidak terdapat akuifer didalamnya. Namun pada kedalaman 89-150 meter dapat dilakukan ekplorasi air tanah dalam, karena pada kedalaman tersebut menunjukkan lapisan Batu apung Berpasir yang bersifat permiabel.

Titik pengukuran DDP-3, menunjukkan lapisan Soil, sisipan Batuapung dan Batupasir berpasir, Breksi dan Batuapung berpasir. Lapisan Soil, terdapat pada pada permukaan hingga 1.4 meter. Selanjutnya terdapat perselingan Batuapung dan Batuapung berpasir pada kedalaman 1.3-29.5 meter. Pada kedalaman ini, dimungkinkan terdapat lapisan akuifer dangkal, walaupun jumlahnya tidak banyak karena dipengaruhi oleh musim. Pada kedalaman berikutnya, yaitu $29.2-71$, terdapat lapisan kedap air/impermiabel berupa lapisan Batuapung. Setelah lapisan tersebut, terdapat lapisan permiabel berupa Batuapung berpasir pada kedalaman 71-180 meter.

\section{DAMPAK DAN MANFAAT KEGIATAN}

Pada hasil pengukuran geolistrik dengan pemodelan 1 dimensi maka didapatkan sebaran lapisan akuifer dalam 2 dimensi seperti yang ditunjukkan pada Gambar 5.

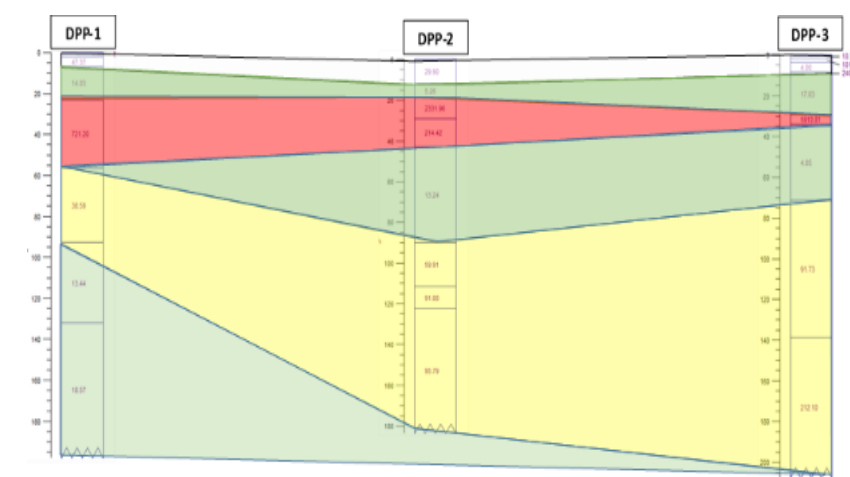

Gambar 5. Pemodelan 2 Dimensi hasil Geolistrik Desa Dadapan Kecamatan Kendal

Pada gambar 5 menunjukkan penampang section 2 dimensi dari hasil interpretasi geolistrik 1 dimensi. Pada lintasan DPP-1, DPP-2 dan DPP-3, menunjukkan lapisan Batu apung dan Breksi saling bersisipan dan searah. Hal ini sesuai dengan kondisi topografi daerah penelitian, dengan kemiringan kearah DPP-3. Lapisan Batuapung berpasir terdapat pada DPP-1, DPP-2 dan DPP-3, yang mengalami penebalan lapisan pada DPP-2 dan DPP-3. Lapisan Batuapung tersebut diperkirakan sebagai lapisan akuifer/permiabel. Penebalan tersebut menunjukkan arah kemiringan lapisan Batuapung berpasir kearah DPP-3, sehingga menurut hukum gravitasi maka air yang terdapat pada lapisan tersebut cenderung kearah DPP-3. Eksplorasi air tanah pada daerah pengukuran tersebut sebaiknya dilakukan pada titik DPP-3 dan DPP-2, karena dari ketebalan lapisan permiabel lebih tebal dan ditunjang oleh kemiringan lapisan permiabel tersebut. Perhitungan perkiraan debit dari ketiga titik tersebut dapat dilihat pada tabel 2 berikut. 
Tabel 2. Perkiraan debit dari ketiga titik pengukuran

\begin{tabular}{|r|l|l|l|r|r|r|}
\hline \multirow{2}{*}{ No } & \multirow{2}{*}{ LOKASI } & \multicolumn{2}{|c|}{ Kedalaman } & \multicolumn{1}{c|}{ DEBIT (LITER/DETIK) } & \multicolumn{1}{c|}{ Q_RAT-RATA } \\
\cline { 3 - 7 } & & & & Q $\min$ & Q_max & (LITER/DETIK) \\
\hline 1 & DDP-1 & 55 & 92 & 1.021 & 4.903 & 2.962 \\
\hline 2 & DDP-2 & 89 & 150 & 1.684 & 8.083 & 4.883 \\
\hline 3 & DDP-3 & 71 & 180 & 3.009 & 14.443 & 8.726 \\
\hline
\end{tabular}

\section{KESIMPULAN}

Dari hasil pengukuran dan pengolahan data geolistrik resistivitas Desa Dadapan Kecamatan Kendal Ngawi Jawa Timur dapat disimpulkan :

1. Lapisan penyimpan akuifer/permiabel merupakan lapisan Batuapung berpasir.

2. Kedalaman akuifer pada masingmasing titik yaitu :

a. DDP-1 : Akuifer dalam pada kedalaman 56.5 sampai 131 meter, pada lapisan Batuapung berpasir

b. DDP-2 : Akuifer dalam pada kedalaman 89 sampai 150 meter pada lapisan Batuapung berpasir.

c. DDP-3 : Akuifer dangkal pada kedalaman 1.3 sampai 29.5 meter dan akuifer dalam pada kedalaman 71-180 meter pada lapisan Batuapung berpasir.

3. Ditinjau dari ketebalan dan kemiringan lapisan permiabel, potensi akuifer dari yang terbesar sampai terkecil adalah DPP-3, DPP-2 dan DPP-1.

\section{PENGHARGAAN}

Ucapan terima kasih kepada pihak yang telah membantu dalam terlaksananya kegiatan penelitian ini. Adapun pihak tersebut :
1. Kepala Desa dan Perangkat Desa Dadapan Kecamatan Kendal kabupaten Ngawi

2. Pejabat Dinas Pekerjaan Umum bagian perumahan dan pemukiman

3. Tim Survey Geosentris Nusantara yang telah membantu dilapangan.

4. Ketua STTI Turen yang telah memberikan dukungan dan kerjasama.

\section{DAFTAR PUSTAKA}

[1] Badan Pusat Statistik Kabupaten Ngawi. 2016. Ngawi Dalam Angka. Ngawi Jawa Timur

[2] Vingoe, P., 1972, Electrical Resistivity Surveying. Geophysical Memorandum

[3] Santoso, Djoko. 2002. Pengantar Teknik Geofisika. ITB, Bandung

[4] Reynold, J.M. 1997. Introduction to Applied and Environmental Geophysics. John Willey And Son, New York.

[5] Datun, M., dkk. 1996. Peta Geologi Lembar Ngawi (Ngawi 1508-4), Jawa Timur Edisi kedua. Pusat Penelitian dan Pengembangan Geologi. Bandung 